\title{
Precipitation: Changing Patterns, Crop Effects and Mitigation: A Brief Review
}

\author{
Gagandeep Kaur ${ }^{1}$ GCG, Simranjit Kaur
}

Ludhiana, India.

\begin{abstract}
Global warming and climate change is a long term change in the weather patterns that characterize the regions of the world. Raised temperature increases the intensity of evaporation and rate of falling of condensed water vapor is 10-25\% folder larger than the rate of evaporation. The associated effects are the changing precipitation and cyclone patterns and the productivity of agriculture. The modest alteration in the precipitation process and winds do not bring much change but consequently leads to dry area becoming more drier and wet areas becoming wetter. These changes are projected to continue in the future. The falling of condensed water vapor occurs as rain rather than rainfall with the rising temperature and snow melting at high rate, there is runoff and risk of flooding that has increased but risk of drought has increased in some areas due to high rate of evaporation.
\end{abstract}

\section{INTRODUCTION}

Current scenario of environment has sticked to reduce greenhouse gases. Many set protocols have been formed to imply this affect. Nevertheless changing in precipitation trends is alarming. As we know the severity of the issue, this paper emphasizes on precipitation which is an utmost proportional factor of both water and climate. The precipitation term refers to the form of solid /liquid of water vapor from atmosphere to surface of the earth. ${ }^{[24]}$

There are many factors that lead forward in process of precipitation viz-a-viz humidity of the surrounding, the trends and intensity of wind. Moreover sunshine also examplify to this.

Furthermore the evaporation from surface and its trends of gathering together also testify to the process of precipitation cloud formation may be the simple part of it.

The continuous exchange of water from oceans and surface of continents to atmosphere comprise of hydrological cycle. Primarily, the intensity of heat/radiation from sun start heating up the water(evaporation), the water droplets from oceans and surface of continents which is proportional to the atmospheric humidity with the help of winds. After reaching at height the vapors cool down and expanded in the process called condensation the cooled water droplets are condensed to become clouds and come back to surface of earth known as precipitation, thus the hydrological cycle is completed in three steps:

1. Evaporation

2. Condensation

3. Precipitation ${ }^{[29]}$

Importance of precipitation in today's life is concerned because the changing pattern of precipitation is striking and their general feature in terms of benefit to earth is altered.

Precipitation has many salient features in running a normal earth system. The global temperature is governed to retain a normal limits by fetching up heat from tropics to high latitudes with the help raised temperature generated by solar radiation by initiating the process evaporation imparting climbing up of heat and falling down of cool winds. These execute the form of convectional currents which heat up the upper layer of atmosphere. For the necessity of global temperature the precipitation has been altered which has affected the temperature severity with respect to temperature of earth. These changes has been collectively called climate alter. 


\section{Precipitation PROCESS}

Suspended water vapor in the atmosphere cools down and condenses in solid or liquid form. This process is termed as precipitation, ${ }^{[30]}$ which comes into effect with the help of temperature, intensity of wind and humidity. Temperature is an important parameter from where the process begins and raises the humidity level in the atmosphere by evaporation. The increased moisture in the air is taken away from surface to atmosphere by moving air wind. As soon as the warm and humid air reaches the dew point i.e. when air stops absorbing water vapor at specific temperature water droplets transform into clouds and come back to earth in solid or liquid form.

A significant relation has been seen between relative humidity (the water vapor present in the air at specific temperature) and precipitation. Greater the relative humidity more would be possibilities of precipitation.

Precipitation takes place in liquid form, when the dew point comes before the freezing point the solid precipitation is witnessed and when it comes into existence after the freezing point.

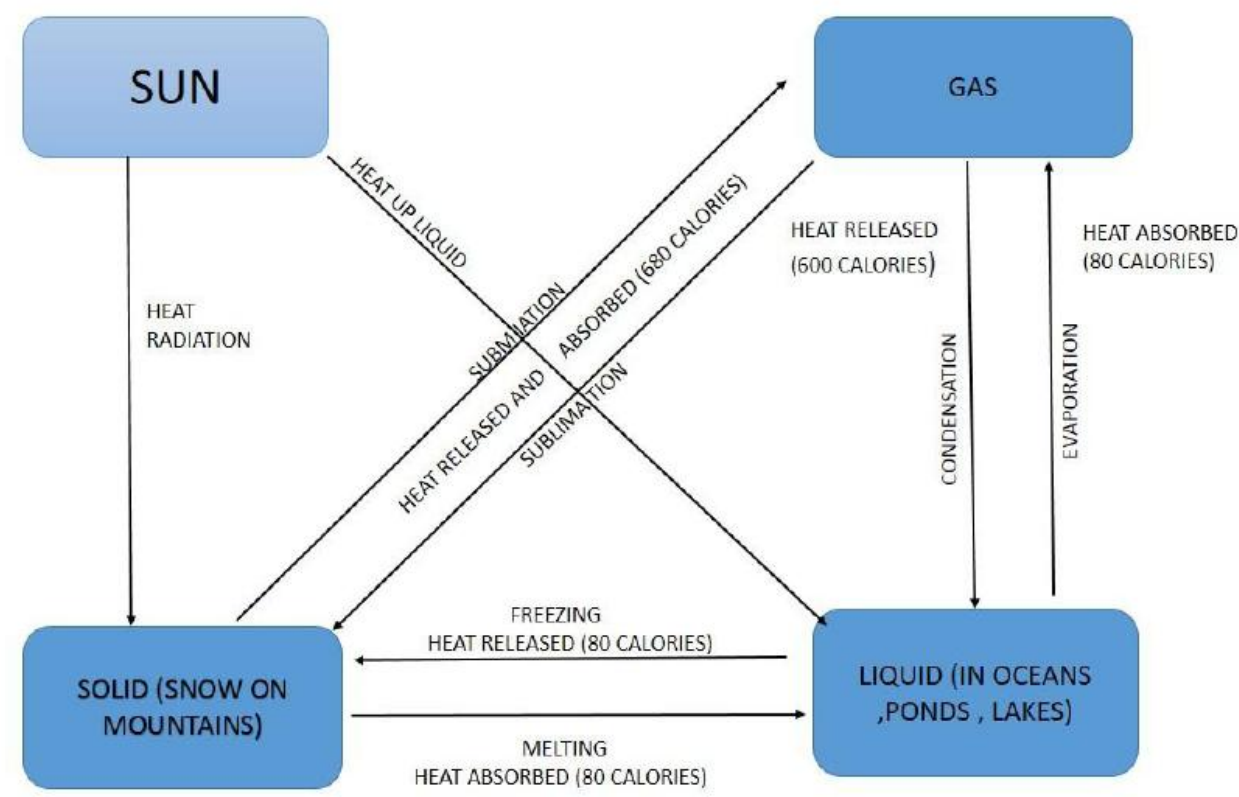

Figuer1. Hydrological Cycle

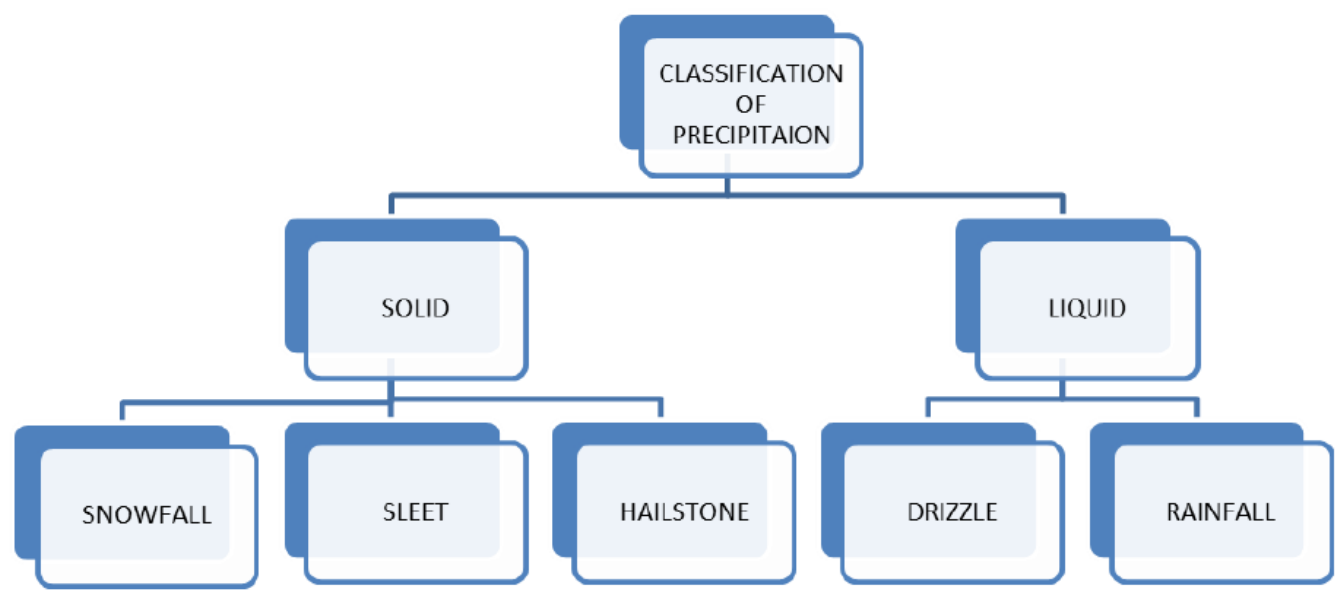

Figuer2. Classification of precipitation

Solid: solid precipitation could be in snowfall, hailstone, and sleet. ${ }^{[18]}$

Snowfall: Condensed water droplets fall on the surface as snowflakes when the temperature near the earth surface comes down less than the freezing point i.e. near the 300 meters. Falling of the snowflakes is snow fall. ${ }^{[24]}$ 
Hails: Passing of the water droplets from the layer whose temperature lowers than the freezing point of atmosphere leads to the rainfall of solid droplets known as hailstones. ${ }^{[24]}$

Sleet: It is the rain that freezes to the ice pellets while falling through the cold layer. It is necessary for the temperature near the earth surface to be cool while little high in the upper layer.

Liquid: liquid precipitation includes drizzle and snowfall ${ }^{[18]}$

Drizzle: It is fall of numerous small sized uniform droplets with a diameter less than 0.02inch.it usually origins from stratus clouds. ${ }^{[24]}$

Rainfall: Rainfall significant type of precipitation. When moisture present in atmosphere is condensed into water droplets and fall on surface in liquid form is known as rainfall. The water droplets are quiet larger than drizzle. ${ }^{[24]}$

\section{Climate Change AND PReCipitation}

Climate change is overwhelming issue which is the consequence of the anthropogenic activities on the planet. The perspective of change in elements of climate is raising the temperature which is resultant of excessive emission of greenhouse gases and their increasing concentration in atmosphere. $\mathrm{CO}_{2}$ is most important while other gases also play an important role. As changes are taking place in mean state of the climate, it has direct impact on the frequency, type and amount of condensed vapors falling on the surface of the earth .Evidently the overall global surface temperature has increased by $0.74^{\circ} \mathrm{C}$ since $19^{\text {th }}$ century and is expected to raise by $1.4^{0} \mathrm{c}-5.8^{0} \mathrm{c}$ by $2100 \mathrm{AD}^{[20]}$.

According to East Anglia's climate research there was erratic growth of temperature after decline from (1945-1973). This drastic change is caused by excessive emission of carbon dioxide, other greenhouse gases and urbanization. This increase in temperature leads to increase in rate of evaporation which results into intense precipitation and causes reduction in duration of rain events without any change in total amount. Increased amount of moisture in air because of increased temperature has weakens the hydrological process and caused delay in onset of monsoon rainfall in some areas.

It has been observed that the water holding capacity of air also increases by $7 \%$ with every $1{ }^{0} \mathrm{C}$ increase in temperature which will have adverse impact on the water cycle ${ }^{[30]}$. As the rate of falling of condensed water vapor is $10-25 \%$ folder larger than rate of evaporation. It is believed that $6 \%$ increase in moisture would cause $20 \%$ increase in rainfall, if all other parameters are unchanged. ${ }^{[23]}$. Heavy rainfall is the consequence of storm circulation but not of evaporation.

Some works involved are listed below:

1. Lack of parity between increase moisture from c-c effect and less resultant change in precipitation is believed that there will be intense nature of precipitation. ${ }^{[26][28]}$

2. There is change from falling of vapor in solid form to liquid especially at the beginning and the end of the season increasing the risk of drought, heat, and wild fires. ${ }^{[21]}$

3. Shifting taking place in the track of storm makes some regions wetter and the other drier leading to complex pattern change. ${ }^{[22][27]}$

4. In some regions the layer of pollution masks round which prevents direct sunlight, decreases evaporation reduce moisture supply to atmosphere.

\section{ObServed Changes in Precipitation}

The hydrological cycle is weakening in the past and it is predicted to be intensify in the future ${ }^{[12]}$. This change is predicted to alter the pattern of the precipitation. This may lead intense rainfall in some regions whereas seasonal shifts in some regions. Studies reveal that there has been overall $2 \%$ increase in the precipitation at global level since $20^{\mathrm{th}}$ century. ${ }^{[13]}$

\subsection{Mid-Latitudes and High Latitudes}

In latitude between $30^{\circ}$ North to $85^{\circ}$ North there is $7 \%$ and $12 \%$ increase in precipitation and in between latitudes $0^{0}$ South to $55^{0}$ South. Precipitation increased by $2 \%{ }^{[5]}$. There is difference in change in precipitation between the northern and southern hemisphere because of the unequal distribution of the land and oceans. 
Increasing quantity of precipitation has been observed in the mid and high latitudes during autumn and spring in northern hemisphere with variations from place to place. As in USA precipitation has increased by $5 \%$ and $10 \%$ but some areas received increased precipitation in the summer season. ${ }^{[5]}$

Regionally precipitation has increased by more than $10 \%$ in Canada over $20^{\text {th }}$ century. There are conflicting reports regarding the precipitation of Canadian prairies. As according to the Akinremi.et al. (1999) there is increase from 1965-1995 but Gan (1998) mentioned increase in precipitation between 1949-1990. ${ }^{[2][7]}$

Decrease in precipitation has been observed over china with $3.9 \%$ per decade fall in the number of days. ${ }^{[33]}$ It has be researches that in USSR the rate of fall in precipitation has been increased by $5 \%$ since 1981. ${ }^{[5]}$

Southwest Australia has also observed decrease in rainy days and the amount of precipitation whereas some areas received the increased amount of precipitation by $15 \%$ to $20 \%$. ${ }^{[10]}$ Notably increase in precipitation has been observed in the northern hemisphere. In most of the regions of this hemisphere receives precipitation as rain rather than snow.

A long term increase has been observed in Argentina in the southern hemisphere since 1900 to 1998. [5]

\subsection{Tropics and Sub Tropics}

There is fall in quantity of precipitation received in the sub tropics from 1980 and even equatorial region recorded fall in precipitation since 1995. ${ }^{[5]}$

In summer monsoon India experienced increase in extreme rain fall moreover shifting of the monsoon from $70 \%$ below than normal levels is predicted. It has an adverse effect on the onset of the monsoon over south east which is believed to be delay by 15 days. ${ }^{[19]}$

Fall in rainy days have experienced in the Southeast Asia and western \& central south pacific but increasing trends has been observed in Fiji and Polynesia.

There has been aridity from long time throughout North Africa, south of Sahara since 1960. ${ }^{[5]}$

Thus the aspect of precipitation is changing. Increase in the torrential rainfall fount to be taking place in some regions, even when mean precipitation is not changing. Although flooding has increased in some areas and in association with cyclone and hurricanes.

\subsection{Impact of Climate Change on Agriculture of World}

Most of the countries are agrarian states and agriculture is only the main source of food to the population of the world. Most of the agriculture depends upon the precipitation which is having adverse impact of the altered climate elements. Changing in the rainfall patterns alter the farming activities, overall it have negative effect on the final yield. ${ }^{[20]}$

The crop production has been declining this century due to changing pattern of the precipitation. Overall productivity has been predicted to fall between 3 to $16 \%$ by 2080. Those developing countries are going to suffer on average $10-25 \%$ decline in 2080 's where the temperature is near or above crop tolerance level. In individual countries like India could see drop of 30 to $40 \%$. $^{[14]}$

But still many countries are tackling with effect of alteration positively. There is decline in rainfall in Australia which is predicted to reduce the productivity. But it is overcome by the process of irrigation. There is increase in rate of precipitation in North America with increase in moderate temperature which may benefit food production. ${ }^{[20]}$

Variations taking place in precipitation has influenced crop and livestock farming. As per observations the onset of the seasonal rainfall has been delayed and number of rainy days are reduced which has vulnerable effect on the yield. The main growing season are March, April, May (MAM) and December, January and February have been declining in Ethiopia, Kenya, Tanzania, Zombie, Malawi since 1980's. In India growing period is June - September and November - January there is increase in the summer rainfall. ${ }^{[11]}$

\subsection{Crop Response to Changing Pattern}

Climate change has increased the temperature which consequently alter the pattern of precipitation. This change has vulnerable effect on the crop yield. As this has effect on the photosynthesis, transpiration, moisture availability. 
Net photo synthesis would increase and transpiration level reduces with increase in $\mathrm{CO}_{2}$ concentration. With every $75 \mathrm{ppm}$ increase in $\mathrm{CO}_{2}$ level would increase the yield by $0.5 \mathrm{t} / \mathrm{h}$ but yield will decrease by $0.6 \mathrm{t} / \mathrm{h}$ for every $1^{0} \mathrm{C}$ increase in temperature. ${ }^{[25]}$

\subsection{Mitigation and Adoption in Agriculture}

[1] Assisting farmer: the farmers could be assisted to cope with the climate risk by providing weather services to farmers can adopt to climate change to some extent by shifting the sowing dates, and to choose varieties with different growth duration or changing crop rotations. ${ }^{[8]}$

[2] Early outbreak warning: there should be early warning on outbreak of diseases and pesticides. Integrated pest management takes into consideration multiple pest in given climate scenario, so pest control strategy should be based on this.

[3] Weather forecasting: seasonal weather forecasting could be used as supportive measure to optimize planting and irrigation patterns.

[4] Efficient use of fertilizers: there should be efficient use of fertilizers such as optimum fertilizers. Application of nitrogenous and potassium fertilizers. This could protect the crops from getting Detroit.

[5] Research and education: more funds should be provided to strengthen research in order to cope with this dynamic world and to overcome this problem of changing patterns of precipitation.

[6] Crop insurance: there is need for providing crop insurance to consumer in order to protect them from the failure of crops. This would encourage them to produce more.

[7] Irrigation facilities: efficient use such as frequent but shallow irrigation drip and sprinkle irrigation for high value crops, irrigation at critical stages. ${ }^{[16]}$

\section{Conclusion}

This paper reveals some connections between climate change and precipitation. Climate change the outcome of the global warming has now started showing its impact across the globe. Consequently it has altered the pattern of precipitation. The forms of precipitation has made transition to great extent. Changes are observed worldwide. Analyses show that heavy and extreme precipitation events has been increased in the regions where the total precipitation has increased. In some regions however the extreme precipitation events has been increased despite the fact that the total precipitation has decreased. It is observed that primarily in the northern hemisphere, in mid and high latitudes areas, significant increase have occurred in the total precipitation derived from heavy and extreme precipitation events.

There is no doubt that the change in pattern of precipitation is the signature of climate change. This has direct influence on the food production across the globe. Agriculture sector is more sensitive to the climate changes because the climate change of a region determines the nature and characteristics of vegetation and crops. Thus to cope with these extreme changes, it need of hour to act globally, nationally and locally.

\section{REFERENCES}

[1] Adamo, Susana B., (2011), Slow-onset hazards and population displacement in the context of climate change.

[2] Akinremi OO, McGinn SM, Cut forth HW (1999), Precipitation trends on the Canadian prairies. J Clim 1 12:2996 - 3003.

[3] Allen MR, Ingram WJ (2002), Constraints on future changes in climate and the hydrologic cycle. Nature 419:224-232.

[4] Christensen, J. H., Hewitson, B., Busuioc, A., Chen, A., Gao, X., Held, R., Jones, R., Kolli, R. K., Kwon, W.-T., Laprise, V., Magana Rueda, L., Mearns, G. G., Menendez, C. G., Rainsanen, J., Rinke, A., Sarr, A., and Whetton, P.: Regional Climate Projections. Climate Change 2007: The Physical Science Basis. Contribution of Working Group I to the Fourth Assessment Report of the Intergovernmental Panel on Climate Change, edited by: Solomon, S., Qin, D., Manning, M., Chen, Z., Marquis, M., Averyt, K. B., Tignor, M., and Miller, H. L., Cambridge University Press, Cambridge, UK and New York, NY, USA, 2007 
[5] Dore MHI (2005), Climate change and changes in global precipitation patterns: What do we know? . Environment International 31: 1167 - 118.

[6] Gan TY (1995), Trends in air temperature and precipitation for Canada and northeastern United States. Int J Climatol R Meteorol Soc 15:1115 - 34

[7] Gan TY (1998), Hydroclimatic trends and possible climatic warming in the Canadian prairies. Water Resour Res vol. 34(11). American Geophysical Union; p. 3009 - 15

[8] Gulatia, A. ,Gupta, P., Jha, M., Sarathi, P.P. \& Vishal, K. ,Impact of Climate Change, Variability, and Extreme rainfall Events on Agricultural Production and Food Security, ISPRS Archives XXXVIII-8/W3 Workshop Proceedings: Impact of Climate Change on Agriculture, : 371.

[9] Held IM, Soden BJ (2006), Robust responses of the hydrological cycle to global warming. J Clim 19:5686-5699.

[10] Hanssen-Bauer I, Førland EJ (1998), Long term trends in precipitation and temperature in the Norwegian Arctic: can they be explained by changes in atmospheric circulation patterns? Clim Res 10:143-53.

[11] Huho JM , Ngaira JKW , Ogindo HO and Masayi N(2012), The changing rainfall pattern and the associated impacts on subsistence agriculture in Laikipia East District, Kenya. Journal of Geography and Regional Planning Vol. 5(7), pp. 198-206,

[12] Huntington TG (2006), Evidence for intensification of the global water cycle: review and synthesis, j.hydrol 319:83-95.

[13] IPCC (2001), Climate change 2001: The scientific basis. Cambridge University Press, UK. p.146.

[14] IPCC (Intergovernmental Panel on Climate Change) (2007), Climate change 2007. The physical science basis. In: Solomon Q, Qin D, Manning M, Chen Z and others (eds) Contribution of Working Group 1 to the 4th assessment report of the Intergovernmental Panel on Climate Change. Cambridge University Press, Cambridge.

[15] IPCC. Climate change 1995: impacts, adaptations, and mitigation of climate change: scientific technical analyses. In: Watson RT, Zinyowera MC, Moss RH, editors. Contribution of Working Group II to the Second Assessment Report of the Intergovernmental Panel on Climate Change [IPCC]. Cambridge, UK Cambridge University Press; 1996.

[16] Kattumuri, Ruth, Food Security and the Targeted Public Distribution System in India, Asia Research Centre Working Paper 38, 3.

[17] Kotlyakov bm (1994).world of snow and ice .285pp"nauka"Moscow.

[18] Liepert BG, Provide M (2009), Do models and observations disagree on the rainfall response to global warming? J Clim 22:3156-3166.

[19] Loo YY, Billa L, Singh A(2015), Effect of climate change on seasonal monsoon in Asia and its impact on the variability of monsoon rainfall in Southeast Asia. Geoscience frontiers 6:817-823.

[20] Mahato A (2014), Climate Change and its Impact on Agriculture. International Journal of Scientific and Research Publications, Volume 4, Issue 4,

[21] Mote PW (2003), Trends in snow water equivalent in the Pacific Northwest and their climatic causes. Geophys Res Lett 30:1601.

[22] Neelin JD, Munnich M, Su H, Meyerson JE, Holloway CE(2006) ,Tropical drying trends in global warming models and observations. Proc Natl Acad Sci USA 103:6110-6115

[23] Ramirez AJ and Finnerty B (1996), Precipitation and water-table effects on agricultural production and economics: Journal of Irrigation and Drainage Engineering [J IRRIG DRAIN ENG], vol. 122, no. 3, pp. 164-171.

[24] Singh M (2005), Dimensions in physical Geography.Rasmeet parkashan $5^{\mathrm{TH}: 342-356 .}$

[25] Sheehy, JE; Elmido, A; Centeno, G; Pablico, P (2005), 'Searching for new plant for climate change'. Journal of Agricultural Meteorology, 60: 463-468.

[26] Trenberth KE (1998), Atmospheric moisture residence times and cycling: implications for rainfall rates and climate change.

[27] Trenberth KE (1999a), Conceptual framework for changes of extremes of the hydrological cycle with climate change. Clim Change 42:327-339.

[28] Trenberth KE, Dai A, Rasmussen RM, Parsons DB (2003), the changing character of precipitation. Bull Am Meteorol Soc 84:1205-1217. 
[29] Trenberth KE(2005) The impact of climate change and variability on heavy precipitation, floods, and droughts

[30] Trenberth KE (2011), Changes in precipitation with climate change. Clim res vol.47:123-138.

[31] Willett KM, Jones PD, Gillett NP, Thorne P (2008), Ecent changes in surface humidity: development of the HadCRUH dataset. J Clim 21:5364-5383.

[32] Yu LS, Weller RA (2007), objectively analyzed air-sea heat fluxes for the global ice-free oceans (1981-2005). Bull Am.

[33] Zeppel MIB (2014), extreme and seasonal changes in precipitation.biogeosciences, 11,3083-3093.

[34] Zhai PM, Sun A, Ren FM, Liu X, Gao B, Zhang Q (1999a). Changes of climate extremes in China. Clim Change; $42: 203-18$ 